\title{
De maatschappelijke relevantie van de accountant - er is meer dan een jaarrekening
}

\section{Peter Eimers en Arco ten Klooster}

SAMENVATTING In de huidige dynamische wereld worden transparantie en het afleggen van verantwoording steeds belangrijker. Verantwoordingen waarbij in toenemende mate behoefte ontstaat aan zekerheid door een onafhankelijke controleur. Dat raakt de kern van het accountantsberoep: een onafhankelijk oordeel geven over een verantwoording ten behoeve van een derde. Was er oorspronkelijk behoefte aan een oordeel over uitsluitend financiële gegevens, nu verbreedt deze informatiebehoefte zich naar maatschappelijk relevante informatie die niet altijd in geldwaarde is uit te drukken. In deze bijdrage worden de ontwikkelingen geschetst rond de veranderende businessomgeving, de daaruit volgende verslaglegging en het toevoegen van zekerheid door de accountant. Deze veranderende rol van de accountant vergt gerichte investeringen in breder opgeleide professionals, samenwerking met specialisten, ontwikkeling van een robuuste methodologie en innovatieve rapportagevormen.

\section{RELEVANTIE VOOR DE PRAKTIJK De veranderende wereld leidt tot nieuwe en andere} behoeften bij gebruikers van informatie. Wil de accountant relevant blijven voor de samenleving, dan moet hij een antwoord hebben op deze ontwikkelingen. De toename van verantwoordingen over niet-financiële informatie vraagt om een accountant die inspeelt op een veranderende behoefte aan zekerheid.

\section{De maatschappelijke rol van de accountant}

In 1623 werd voor de eerste keer het toneelstuk 'Timon of Athens' van William Shakespeare opgevoerd. Hierin zegt Flavius tegen zijn leenheer Timon: 'If you suspect my husbandry of falsehood, call me before the exactest auditors and set me on the proof.' Kennelijk is het vakgebied auditing $^{1}$ van alle tijden. De accountant speelt een belangrijke rol in de relatie tussen opsteller en gebruiker van informatie als het gaat om betrouwbaarheid van de verantwoording. Ooit was deze informatiebehoefte beperkt omdat de directeur ook de aandeelhouder was, maar door de scheiding van leiding en eigendom van de onderneming werd de rol van de accountant belangrijker. De agencytheorie leert ons dat de ondernemingsleiding in een fiduci- aire relatie staat ten opzichte van de aandeelhouders (Watts en Zimmerman, 1986), maar naarmate de kapitaalverschaffers op grotere afstand kwamen te staan, nam de behoefte aan onafhankelijke toetsing toe. De accountant werd een spil in het economische verkeer.

Dit heeft geleid tot een bepaalde taakopvatting van de accountant, maar het is belangrijk daarbij aan te merken dat die taak aan verandering onderhevig kan zijn. De accountant heeft namelijk te maken met verwachtingen die gebaseerd zijn op verslaggevingsregels die uiteindelijk gedragen moeten worden door de samenleving. Ook het Burgerlijk Wetboek definieert de criteria zoals die gelden voor financiële verslaggeving primo in relatie tot de samenleving, namelijk door te spreken van 'normen die in het maatschappelijk verkeer als aanvaardbaar worden beschouwd' (BW2:362). De maatschappelijke functie van de accountant bestaat hieruit dat de samenleving een vertrouwen in hem of haar stelt om als onafhankelijke deskundige de betrouwbaarheid van informatie vast te stellen die van belang is voor het maatschappelijk verkeer.

De accountant werkt dus vanuit een vertrouwensbasis, die verder reikt dan de eerder beschreven economische basis die het uitgangspunt vormt in de agencytheorie. De maatschappelijke relevantie van de accountant is afhankelijk van de waarde die wordt gehecht aan zijn oordeel. Zou hij zijn werk niet goed doen, dan neemt die relevantie af. Maar zou zijn oordeel beperkt blijven tot informatie die er minder toe doet, dan neemt die maatschappelijke relevantie evenzeer af. Daarom dient de accountant zich bewust te zijn van de verwachtingen in de samenleving en zijn rol daarbij. Hier praten we al over sinds de jaren dertig van de vorige eeuw, toen Limperg zijn 'Leer van het gewekte vertrouwen' uitwerkte. De waarschuwingen van toen gelden nog onverminderd (Limperg, 1932/1933): de accountant moet zijn werk goed doen en ervoor waken dat hij niet te hoge verwachtingen oproept. Hij zal zich steeds 
bewust moeten zijn van de reikwijdte van zijn conclusies, ook als dat betekent dat de onzekerheid over de betrouwbaarheid van de informatie niet weggenomen kan worden. Dit is een van de belangrijkste grondslagen van het accountantsberoep. Het noopt tot voorzichtigheid, maar het zou niet moeten leiden tot een soort principiële terughoudendheid bij ontwikkelingen binnen het vakgebied. Dat zou ten koste gaan van de maatschappelijke relevantie van de accountant, zeker in de dynamische wereld van vandaag de dag.

In deze bijdrage wordt allereerst ingegaan op relevante veranderingen in de zakelijke omgeving (paragraaf 2). Daarna wordt betoogd dat dit ook effecten heeft op de aard, omvang en timing van verslaggeving (paragraaf 3), en daaruit volgend op de rol van de accountant (paragraaf 4). Deze bijdrage sluit af met een toekomstperspectief, waarin de bredere verslaggeving en de rol van de accountant samenkomen.

\section{De wereld verandert}

De zakelijke omgeving is in de afgelopen jaren sterk veranderd. De wereld globaliseert en digitaliseert in een hoog tempo. Veranderingen zijn van alle tijden maar lijken elkaar steeds sneller op te volgen. Zij gaan gepaard met onzekerheden en laten zich vertalen in kansen en bedreigingen (Wallage, 2008). Wie 15 jaar geleden heeft kunnen inspelen op het aanjagend en doordringend effect van het fenomeen internet op business, informatie en rapportage, is nu spekkoper. De introductie van internet in het midden van de jaren negentig van de vorige eeuw heeft als katalysator gewerkt voor het stroomlijnen van de zakelijke activiteiten en administratieve processen. Globalisering en digitalisering hebben gezorgd voor meer wereldwijd opererende bedrijven en een samenleving die meer op netwerken is georiënteerd. Dat geldt niet alleen voor de multinationale onderneming, maar ook voor de plaatselijke onderneming die leveranciers en afnemers in binnen- en buitenland heeft en met hen via internet communiceert. Daar komt bij dat contractuele relaties ingewikkelder zijn geworden en financiële instrumenten om kapitaal te verkrijgen en risico's af te dekken, veel complexer zijn dan voorheen. Denk hierbij aan renteswaps, leasecontracten en kredietovereenkomsten, maar ook aan uitbestede processen (outsourcing) of de problematiek over verantwoordelijkheden in de productieketen rond kinderarbeid of chemische stoffen in producten. In een aantal gevallen is hier sprake van gebruik van publieke gelden, waarbij ook doelmatigheid en rechtmatigheid een rol spelen.

De ontwikkelingen staan niet stil. Een voorbeeld hiervan is de ontwikkeling van de financiële rapportage op basis van
XBRL. Nu nog stelt een onderneming een jaarrekening op, maakt een belastingaangifte, deponeert de jaarrekening bij het handelsregister, verschaft relevante kredietinformatie aan de bank, geeft statistieken door aan het CBS en informeert beleggers. Telkens weer een andere verantwoording. Met XBRL is het mogelijk dat gebruikers van informatie zich allemaal kunnen baseren op dezelfde set aan data en al naar gelang het doel overzichten kunnen genereren. Deze geluiden zijn al een decennium te horen, maar met het standard business reporting (SBR)-project van de Nederlandse overheid wordt dit binnenkort werkelijkheid, met concrete uitwerkingen door de banken en convenantaangiften ten behoeve van de fiscus.

Dit zijn technologische ontwikkelingen die nieuwe mogelijkheden creëren voor de bedrijfsvoering. Maar ook op andere terreinen hebben ingrijpende veranderingen plaatsgevonden. In dit kader wijzen we in het bijzonder op wat de democratisering van de moraal genoemd is (Van Luijk, 2003). De verwachtingen van het maatschappelijk verkeer ten aanzien van het gedrag van een onderneming zijn diverser geworden. Niet alleen 'nongouvernementele organisaties' (NGO's) en andere belangengroeperingen stellen vandaag de dag hoge eisen aan de bedrijfsvoering, ook andere stakeholders als medewerkers en consumenten zijn gedurende de laatste decennia mondiger geworden. Dit hangt samen met een aanhoudende ontwikkeling waarbij moreel gezag langzaam maar zeker wordt overgeheveld van de traditionele morele autoriteiten zoals kerk, overheid en wetenschap, naar het individu. Deze verschuivingen van technologische en sociaal-politieke aard versterken elkaar. Ze zorgen ervoor dat ondernemingen zich gesteld zien voor geheel andere en nieuwe vragen (Van Luijk en Schilder, 1997). Technologische vernieuwing plaatst ondernemingen in nieuwe situaties. Door veranderde verwachtingen van stakeholders volstaan 'oude' antwoorden opeens niet meer. Aan welke juridische verplichtingen heb ik te voldoen op het gebied van mijn mondiale e-business? Hoe ver kun je gaan met genetische modificatie? Is het geoorloofd gebruik te maken van wettelijk toegestane kinderarbeid in lagelonenlanden? Mag ik dure relatiegeschenken aannemen als dat conform de gewoonten van het land is? Met betrekking tot dit soort vragen bieden aloude waarden en normen vaak geen soelaas. Dit soort vragen heeft ertoe geleid dat er tegenwoordig veel aandacht is voor de maatschappelijke aspecten van ondernemen. ${ }^{2}$

In dit krachtenveld van stakeholdergroepen krijgen organisaties zo te maken met veel verschillende en vaak ook tegenstrijdige belangen en verwachtingen. Bij gebrek aan een vast moreel kader is ethiek in deze tijd voor een belang- 
rijk deel een kwestie geworden van afspraken maken over wat wel en wat niet kan en deze tendens houdt niet op bij de voordeur van organisaties. Ondernemingen staan continu voor de uitdaging om tegemoet te komen aan de verwachtingen van hun stakeholders. Als reactie hierop en om invulling te geven aan hun 'corporate responsibility' - nemen steeds meer organisaties hun toevlucht tot maatschappelijke verslaglegging. Hiermee wordt bedoeld dat ondernemingen steeds meer en steeds vaker maatschappelijk relevante informatie naar buiten brengen. Uit recent onderzoek van Craib en PwC blijkt dat inmiddels $74 \%$ van ondernemingen in de Standard \& Poor's Europe 350 Index een maatschappelijk verslag publiceert (Craib en $\mathrm{PwC}$, 2009). Maatschappelijke verslaggeving stelt de onderneming in staat om uitleg te geven op beleidsaspecten die verder reiken dan het traditioneel financieel-economische speelveld van de onderneming. Het is inmiddels een beproefde methode om stakeholders mee te nemen in de maatschappelijke dilemma's waarvoor de ondernemingsleiding zich gesteld ziet.

\section{Verslaggeving verandert}

De veranderende wereld heeft gevolgen voor de aard, omvang en timing van rapportages. De globalisering van het bedrijfsleven heeft geleid tot een toenemende behoefte aan een wereldwijde standaard voor financiële verslaggeving, wat uiteindelijk de International Financial Reporting Standards (IFRS) zijn geworden. Tevens is door de behoefte aan meer en snellere informatie, de frequentie van verslaggeving toegenomen. Dit komt onder meer tot uitdrukking in wettelijke bepalingen over publicatie van tussentijdse berichten en over het communiceren van koersgevoelige informatie. De beschikbaarheid van internet maakt het beleggers mogelijk om sneller informatie ter beschikking te krijgen en sneller op de beurs te handelen. De dynamiek in verslaggeving is dus toegenomen, met gevolgen voor de onderneming die de financiële verslaggeving opstelt en voor de accountant die deze verslaggeving controleert.

Door de toegenomen hoeveelheid en complexiteit van contractuele relaties en de onderlinge afhankelijkheid in de keten van informatieverschaffing, leggen steeds meer ondernemingen en publieke entiteiten verantwoording af over hun doen en laten. ${ }^{3}$ De maatschappelijke behoefte aan betrouwbare informatie neemt op alle fronten sterk toe. Niet-financiële informatie wordt steeds belangrijker voor ondernemingen en publieke entiteiten, voor zowel de interne sturing als externe verantwoording (NIVRA, 2009). Dit is te zien in separate maatschappelijke verslagen, maar ook in diverse andere specifieke verantwoordingen waar belanghebbenden gebruik van maken.

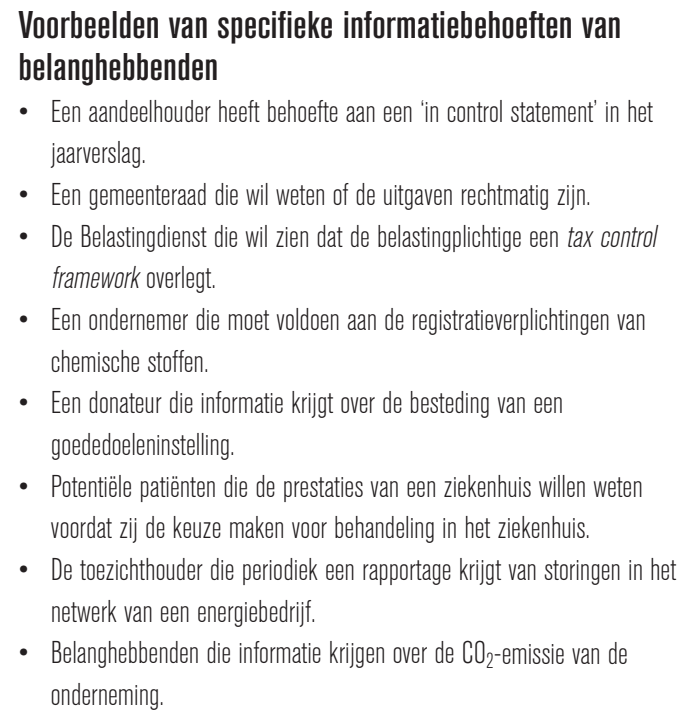

- Een aandeelhouder heeft behoefte aan een 'in control statement' in het jaarverslag.

- Een gemeenteraad die wil weten of de uitgaven rechtmatig zijn.

- De Belastingdienst die wil zien dat de belastingplichtige een tax control framework overlegt.

- Een ondernemer die moet voldoen aan de registratieverplichtingen van chemische stoffen.

- Een donateur die informatie krijgt over de besteding van een goededoeleninstelling.

- Potentiële patiënten die de prestaties van een ziekenhuis willen weten voordat zij de keuze maken voor behandeling in het ziekenhuis.

- De toezichthouder die periodiek een rapportage krijgt van storingen in het netwerk van een energiebedrijf.

- Belanghebbenden die informatie krijgen over de $\mathrm{CO}_{2}$-emissie van de onderneming.

Kenmerkend verschil ten opzichte van financiële verslaggeving is dat bij jaarrekeningen de grondslagen van verantwoording zijn uitgekristalliseerd, terwijl bij deze relatief nieuwe thema's de normen in ontwikkeling zijn. Een voorbeeld hiervan zijn de Global Reporting Initiative (GRI)-standaarden die de grondslagen weergeven voor veel corporate responsibility (CR)-verslagen.

Het ontbreken van uitgekristalliseerde normen neemt niet weg dat deze 'nieuwe' informatie wel relevant moet zijn voor de gebruikers van die informatie, anders heeft publicatie geen nut. Verwachten gebruikers van deze informatie dat de gegevens betrouwbaar zijn? Het is de vraag of de opstellers van die informatie dat kunnen waarmaken. Uit een recent onderzoek van Eumedion, NIVRA en VBA bleek dat de institutionele belegger de jaarrekening voor kennisgeving aanneemt, maar de echte belangstelling uitgaat naar andere zaken dan de financiële prestaties: de kwaliteit van het risicomanagement, corporate governance, duurzaamheidscriteria. Uit het onderzoek bleek dat veel beleggingsanalisten er vanuit gaan dat de accountant dergelijke informatie ook daadwerkelijk controleert, terwijl dat zelden het geval is (Eumedion, 2010). Kennelijk is er een verwachtingskloof ontstaan tussen wat de accountant doet met het directieverslag (de verplichte consistentietoets met de jaarrekening uit het Burgerlijk Wetboek) en wat men feitelijk verwacht (controle).

Dit komt des te meer naar voren naarmate meer maatschappelijke informatie wordt opgenomen in het directieverslag (zie: Dekker, 2010). Deze trend is ontegenzeggelijk waarneembaar, terwijl de werkzaamheden van de accountant er in de meeste gevallen niet door zijn veranderd. In de 
afgelopen jaren is het besef gegroeid dat het bedrijfsleven een verantwoordelijkheid draagt om de wereld op zijn minst net zo achter te laten voor toekomstige generaties als hoe hij die aantrof. Dat wordt niet alleen verlangd door de op dit moment betrokkenen bij de onderneming. Het is ook van strategisch belang voor de betrokkenen in de toekomst van de onderneming. Vanuit een strategisch perspectief gaat 'corporate responsibility' over het sturen op de niet-financiële resultaatgebieden van de onderneming. Dat impliceert dat betrouwbare informatie voorhanden moet zijn. Daarbij gaat het niet alleen om interne managementinformatie, maar het gaat ook over externe verslaggeving, die de belanghebbenden in staat moet stellen om zich een goed beeld van de onderneming te vormen. Hier ligt een taak voor de maatschappelijk relevante accountant. Als in het directieverslag wordt toegelicht in welke mate een onderneming succesvol is in het terugdringen van de afhankelijkheid van fossiele brandstoffen, dan zal dat niet in tegenspraak zijn met de jaarrekening. Dat zou echter geen vrijbrief mogen zijn om als accountant deze informatie als niet relevant terzijde te leggen! Hij zal dan een aantal vervolgstappen moeten nemen conform controlestandaard 720.4

Inmiddels bestaat er een breed draagvlak voor 'maatschappelijke verslaggeving'. Zo heeft dit onderwerp in de landelijke politiek de nodige aandacht gekregen. $\mathrm{Al}$ in 2003 heeft de Raad voor de Jaarverslaggeving (RJ) hiervoor een conceptueel kader ontwikkeld, dat werd uitgewerkt in een 'Handreiking voor maatschappelijke verslaggeving'. Ook de Sociaal Economische Raad (SER) vindt verdere stimulering en facilitering van maatschappelijk ondernemen geboden. In 2008 heeft de SER de RJ verzocht om aanbevelingen te ontwikkelen voor rapportage van bedrijven over hun internationale ketenbeheer als aanvulling op Richtlijn 400.

\section{Rol van de accountant verandert}

De veranderende omgeving en de daaruit volgende veranderingen in verslaggeving hebben ook hun weerslag gehad op de werkzaamheden van de accountants. Dit geldt in de eerste plaats voor de controle van de jaarrekening. De voor accountants geldende controlestandaarden zijn dit jaar nog aangepast aan de complexer geworden wereld. De nieuwe controlestandaarden geven meer duidelijkheid aan controlerend accountants en hun toezichthouders, maar eveneens aan de gebruikers van de jaarrekening. Ze geven explicieter aan wat van de accountant wordt verwacht bij het uitvoeren van zijn of haar controlewerkzaamheden. De standaarden maken nog meer dan voorheen duidelijk dat 'auditen nog steeds met gezond verstand controleren' is (Eimers en Drupsteen, 2010). In deze nieuwe standaarden wordt expliciet van de accountant verwacht om meer en diepgaandere procedures uit te voeren rond de controle van fair values, van verbonden partijen en groepsjaarrekeningen.

Voor het aan de jaarrekening gekoppelde jaarverslag geldt iets anders. De accountant is blijkens de wet belast met de controle van de jaarrekening, maar niet van het jaarverslag. Wel is de accountant bij wet verplicht om vast te stellen dat het jaarverslag verenigbaar is met de jaarrekening, hetgeen dus niet inhoudt dat de accountant de informatie in het jaarverslag met dezelfde diepgang bekijkt als de informatie in de jaarrekening. Ook al zou de accountant wel diepgaander onderzoek doen naar het jaarverslag, dan kan het zijn dat de accountant geen conclusie kan trekken door het ontbreken van een voldoende uitgekristalliseerde toetsingsnorm die voldoet aan paragraaf 36 van het Stramien voor assurance-opdrachten: relevant, volledig, betrouwbaar, neutraal, begrijpelijk (NIVRA 2010a).

Naast de door de wet opgelegde controle van de jaarrekening, kan er sprake zijn van vrijwillige toetsing van verantwoordingen of verantwoordingen voor algemeen gebruik of voor een specifieke gebruiker, zoals OPTA, NMa of Nederlandse Emissieautoriteit. Het gaat hierbij in een aantal gevallen om financiële gegevens, maar vaak ook om niet-financiële informatie die moet worden verantwoord. In deze gevallen wordt de verantwoording en de daaraan gekoppelde rapportage door de accountant veelal niet zichtbaar voor het brede maatschappelijke verkeer, maar wel voor de genoemde gebruiker van de verantwoording.

Het vrijwillig laten verifiëren van de betrouwbaarheid van gerapporteerde informatie kan om verschillende redenen belangrijk zijn voor ondernemingen. In de eerste plaats draagt het bij aan de geloofwaardigheid van de (maatschappelijke) verslaggeving. Naarmate niet-financiële informatie meer gebruikt wordt door belanghebbenden, groeit de behoefte hieraan. Zo is de Vereniging van Beleggers voor Duurzame Ontwikkeling (VBDO) bijvoorbeeld een uitgesproken voorstander van assurance door een onafhankelijke partij. Versterkend werkt eveneens de ontwikkeling dat de variabele beloning van bestuurders mede afhankelijk is gesteld van niet-financiële resultaten. Vanzelfsprekend is het dan van belang om te kunnen beschikken over betrouwbare informatie. Veel ondernemingen zijn inmiddels zover dat hun CR-beleid is vertaald in concrete doelstellingen. Om hier effectief op te kunnen sturen, is betrouwbare periodieke managementinformatie nodig. Een onafhankelijke derde die assurance verleent, draagt daaraan bij door de volledigheid en de betrouwbaarheid van informatie vast te stellen. Daarbij worden de onderliggende interne beheersingssystemen getoetst op een manier die vergelijkbaar is met die rondom financiële verslaggeving. 
Die onafhankelijke derde blijkt steeds vaker een accountant te zijn. Ongeveer $60 \%$ van de assurancerapporten die worden afgegeven bij maatschappelijke verslaggeving wordt tegenwoordig uitgebracht door een accountantsorganisatie (Craib en PwC, 2009). Dat is minder vanzelfsprekend dan het wellicht op het eerste gezicht lijkt. Hoewel accountantsorganisaties zich hier al lange tijd mee bezighouden, werd in het verleden vaker dan nu ook aan maatschappelijke organisaties of technische ingenieursbureaus gevraagd om een onafhankelijk rapport af te geven bij maatschappelijke verslaggeving. De reden hiervoor was dat materiedeskundigheid van doorslaggevend belang werd geacht om een zinvol oordeel te kunnen geven. Met name in Angelsaksische landen worden externe verificaties ook uitgevoerd door gespecialiseerde CR-consultants, maar ook daar neemt het aandeel van accountants toe (Craib en PwC, 2009). De maatschappelijk relevante accountant heeft zich op dit punt dus moeten ontwikkelen! Dat ondernemingen tegenwoordig steeds vaker ook hun accountant vragen om assurance bij maatschappelijke verslaggeving, hangt samen met ten minste drie redenen:

- Materiedeskundigheid alleen is niet voldoende. Met het toenemen van de professionaliteit van maatschappelijke verslaggeving wordt de verificatie ervan ook complexer. Moderne accountantsorganisaties zijn bij uitstek in staat om multidisciplinaire teams samen te stellen vaak ook internationaal - die gezamenlijk de assuranceopdracht uitvoeren. De expertise op het gebied van assurance wordt gecombineerd met specifieke kennis van bijvoorbeeld $\mathrm{CO}_{2}$-emissies of arbeidsrechten. Een voorbeeld hiervan is de verificatie van $\mathrm{CO}_{2}$-emissierechten bij luchtvaartmaatschappijen. ${ }^{5}$

- Het is belangrijker geworden dat de assuranceaanbieder onafhankelijk is van de onderneming. Accountantsorganisaties die jaarrekeningcontroles uitvoeren, zijn gehouden aan een robuust regime op dit gebied. Wanneer de niet-financiële informatie in het financiële verkeer een belangrijker rol gaat spelen, wordt de rol van een onafhankelijke derde steeds meer gewenst en is een directe link met de jaarrekeningcontrole onontbeerlijk om inefficiëntie in de uitvoering te voorkomen.

- Accountantsorganisaties zijn ook zelf eerder geneigd om deze rol op zich te nemen. Niet-financiële assurance ligt in het verlengde van de traditionele assurancewerkzaamheden. Ook $\mathrm{CO}_{2}$-cijfers kunnen aangesloten worden op brondocumentatie en zijn geschikt om analytische werkzaamheden op uit te voeren. Beroepsorganisaties hebben dit onderkend en hebben specifieke standaarden ontwikkeld. In Nederland heeft het NIVRA in 2007 de assurancestandaard 3410N uitgegeven: 'Assuranceopdrachten inzake maatschappelijke verslagen'. Met deze specifieke standaard - die als een verbijzondering van de internationale assurancestan- daard 3000 beschouwd kan worden - loopt Nederland internationaal gezien voorop. Standaard $3410 \mathrm{~N}$ onderkent het speciale karakter van maatschappelijke verslaggeving en schrijft een model voor waarbij de registeraccountant samenwerkt met materiedeskundigen. Met Standaard $3410 \mathrm{~N}$ in de hand wordt het voor accountants gemakkelijker om aantoonbaar een deugdelijke grondslag te vinden voor het afgeven van een CR-assurancerapport.

\section{Hoe nu verder?}

In de publicatie 'Integrated reporting: What does your reporting say about you?' (PricewaterhouseCoopers, 2010) wordt geconcludeerd dat de meerderheid van de FTSE 350-ondernemingen (beursgenoteerde ondernemingen in Groot-Brittannië) meer een 'ticking the boxes'-mentaliteit hebben om te voldoen aan regelgevende verplichtingen, maar moeite hebben om helder te communiceren naar de belangrijkste stakeholders wat ze werkelijk moeten weten op gebieden als prestatie, risicohouding, governance en realiseren van de uitgezette strategie.

Leidt de noodzaak tot meer communicatie over deze onderwerpen tot een verdere uitbreiding van de al uitdijende verslaggeving? Het risico hierbij is dat een informatieoverload ertoe leidt dat we door de bomen het bos niet meer zien en dat een focus op compliance ontstaat in plaats van op relevantie. De kunst zit in het integreren van verantwoordingen. In het afgelopen jaar hebben we hiervan al enkele voorbeelden gezien. Het Havenbedrijf Rotterdam heeft over 2009 een volledig geïntegreerd jaarverslag en maatschappelijk verslag gepubliceerd met een accountantsverklaring die zowel de jaarrekening alsook de (niet-)financiële informatie in het jaarverslag bestrijkt. De Van Gansewinkel Groep heeft vanuit de maatschappelijke visie ('afval bestaat niet') een geïntegreerd MVO-verslag/jaarverslag gepubliceerd waaraan een verkorte jaarrekening is toegevoegd. Deze ontwikkelingen passen in een internationale trend van ondernemingen die zich herpositioneren in hun verslaggeving (Eccles en Krzus, 2010).

Hoe ingewikkeld of eenvoudig kan het? De al eerder genoemde RJ 400 kan hiervoor een aanknopingspunt zijn. Deze richtlijn heeft het directieverslag als uitgangspunt voor het afleggen van verantwoording over het doen en laten van de onderneming. In de herziene RJ40o zoals onlangs gepubliceerd en in de bijbehorende 'Handreiking voor Maatschappelijke Verslaggeving' waarin een concreet kader wordt aangereikt dat hiervoor steun en richting kan geven, worden belangrijke aanbevelingen gedaan, waaronder:

- het opnemen van een toelichting met betrekking tot maatschappelijke aspecten van ondernemen inclusief internationaal ketenbeheer (al. 117); 
- voor zover relevant voor de aard van de ondernemingsactiviteiten, naast algemene maatschappelijke aspecten, aandacht besteden aan milieu-, sociale- en economische aspecten (al. 119);

- in de toelichting op maatschappelijke aspecten een onderscheid maken tussen de eigen bedrijfsvoering en de internationale keten waarin de onderneming opereert (al. 120);

- in de toelichting ingaan op het gevoerde en te voeren maatschappelijke beleid, de organisatie en uitvoering ervan en de dialoog met belanghebbenden (al. 121).

Is de cirkel dan rond, met samenvoeging van rapportages tot één integrale verantwoording? Naar onze mening is het streven naar één integrale verantwoording een uitstekende mogelijkheid om het doen en laten van ondernemingen samenhangend te presenteren, zowel financieel als niet-financieel. Maar het moet niet een oefening op zich worden om verschillende verantwoordingen te integreren. Niet integreren om het integreren, alleen als het strategisch en maatschappelijk relevante informatie geeft.

De veranderende omgeving vereist ook een ander profiel van de accountant. Natuurlijk moet een accountant cijfermatig goed onderlegd zijn, maar de toenemende complexiteit vraagt om accountants die breder zijn georiënteerd. Ze moeten inspelen op ontwikkelingen, verbanden zien en oplossingen bieden voor de samenleving. De accountant van de toekomst is daarom een professional die meer dan voorheen proactief handelt vanuit een maatschappelijke oriëntatie, veelvuldig samenwerkt in multidisciplinaire teams en een diepgaandere kennis heeft van informatietechnologie (Eimers, 2008).

Op vaktechnisch vlak zullen accountants slagen moeten maken om relevant te blijven. Het ontbreken van een toetsingsnorm verhindert een conclusie van de accountant, maar een norm hoeft niet wettelijk te zijn ingekaderd. Dit vergt een investering van accountants, maar ook afstemming met belangrijke stakeholders in de samenleving over welke randvoorwaarden gesteld worden aan toetsingsnormen.
Ten slotte zullen accountants hard moeten werken aan de wijze waarop de accountant zijn bevindingen rapporteert aan de belanghebbenden. Hoe communiceert de accountant? Als we kijken naar de belangrijkste uiting van de accountant - de accountantsverklaring bij de jaarrekening - dan zien we dat de accountantsverklaring in de tijd in lengte is toegenomen. Wie accountantsverklaringen over de jaren naast elkaar legt, ziet dat het start met 'akkoord en goed bevonden' en de tekst van de accountantsverklaring in de tijd is uitgedijd tot een omvang die niet meer in een normaal lettertype op één pagina past. Inmiddels komt er overigens steeds meer kritiek op de tekst van de accountantsverklaring in zijn huidige omvang (Eimers, 2008).

In een veranderende wereld waar de jaarrekening niet meer alleen op papier wordt uitgegeven maar ook op internet - al dan niet interactief - en andere verantwoordingen dan jaarrekeningen, past een fundamentele discussie over de gevolgen hiervan voor de uitingen van de accountant en daarmee ook de accountantsverklaring. Een van de hierin mee te nemen elementen is de vraag op welke wijze de accountant moet rapporteren indien er sprake is van integrated reporting. Komt er één geïntegreerde accountantsverklaring voor zowel de financiële als niet-financiële verantwoordingen? De toekomst zal het leren.

\section{Samenvatting en conclusie}

De veranderende wereld leidt tot een verbreding van verslaggeving die steeds vaker betrekking heeft op nietfinanciële informatie. Wil de accountant relevant blijven, dan zal hij moeten inspelen op deze nieuwe ontwikkelingen.

Prof. dr. P.W.A. Eimers RA is partner bij PWC, hoogleraar Auditing aan de Vrije Universiteit te Amsterdam en voorzitter van het Adviescollege Beroepsreglementering van de NBA (de nieuwe naam voor NIVRA en NOvAA). Drs. A.C. ten Klooster RO is director Sustainability bij PwC en is voorzitter van de werkgroep RJ 400 'maatschappelijke verslaggeving' van de Raad voor de Jaarverslaggeving. 


\section{Literatuur}

- Craib Design \& Communications and PricewaterhouseCoopers (2009), CSR Trends 3 , a comprehensive survey of corporate social responsibility report trends, benchmarks and best practices, Toronto, zie: www.craib.com. - Dekker, G. (2010), Toekomst jaarverslag in acht vragen, De Accountant, september, pp. 12-16.

Eccles, R.G. en M.P. Krzus (2010), One report - Integrated reporting for a sustainable strategy, New Jersey: John Wiley \& Sons, Inc.

- Eimers, P.W.A. (2008), De betekenis van de accountant in een dynamische wereld, Vrije Universiteit Amsterdam, inaugurele rede, zie: http://dare.ubvu.vu.nl/bitstream/1871/ 13103/1/0ratie\%20Peter\%20Eimers.pdf.

- Eimers, P.W.A. en J.T. Drupsteen (2010), Nieuwe controlestandaarden bevestigen controle met gezond verstand, Accountancynieuws, nr. 1 , 15 januari, pp. 24-26.

- Eumedion (2010), Niet-financiële informatie steeds belangrijker voor beleggers (persbericht 2 juni Eumedion, NIVRA en VBA), zie: www. eumedion.nl.

- Global Reporting Initiative (2006), Substainability Reporting Guidelines, Amsterdam, zie: www.globalreporting.org.

- Limperg, Jr., Th. (1932/1933), De functie van de accountant en de leer van het gewekte vertrouwen, Maandblad voor Accountancy en
Bedrijfshuishoudkunde, februari en oktober 1932, oktober en november 1933; herdrukt in de bundel: '1924 MAB 1960, inhoudende een aantal bijdragen gedurende deze jaren verschenen in het Maandblad voor Accountancy en Bedrijshuishoudkunde', deel 2, Accountancy, Purmerend: Muusses, pp. 137-169.

- Luijk, H.J.L van (1993), Om redelijk gewin; Oefeningen in bedrijfsethiek, Amsterdam: Boom. - Luijk, H.J.L. van, en A. Schilder (1997), Patronen van verantwoordelijkheid, Schoonhoven: Academic Service. - NIVRA, Koninklijk (2009), Meer dan euro's alleen, Amsterdam, zie: www.nivra.nl.

- NIVRA, Koninklijk (2010a), Handleiding Regelgeving Accountancy, Amsterdam, zie: www.nivra.nl.

- NIVRA, Koninklijk (2010b), Praktijkhandrejking 1109 - De verantwoordelijkheid van de accountant bij de toetsing van de in het jaarverslag opgenomen corporate governanceinformatie, Amsterdam, zie: www.nivra.nl.

- PricewaterhouseCoopers (2010), Integrated reporting - What does your reporting say about you?, zie: http://www.corporatereporting.com/ integrated_reporting_2010.html.

Raad voor de Jaarverslaggeving (2009), Handreiking voor Maatschappelijke verslaggeving, zie: www.rjnet.nl.
- Raad voor de Jaarverslaggeving (2009), Richtlijn 400 - Maatschappelijk verantwoord ondernemen, Amsterdam, zie: www.rinet.nl. - Sociaal Economische Raad (2000), De winst van waarden, Advies nr. 2000/11; zie: http:// www.ser.nl/nl/publicaties/adviezen/2000-2007/ 2000/b19054.aspx.

- Sociaal Economische Raad (2008), Duurzame globalisering: een wereld te winnen, Advies nr. 2008/06, juni; zie: http://www.ser. nl/nl/publicaties/adviezen/2000-2007/2008/ b26895.aspx.

- Sociaal Economische Raad (2008), Verklaring internationaal maatschappelijk verantwoord ondernemen, zie: http://www.ser nl/nl/publicaties/overige/2000-2008/2008/ b27428.aspx.

- Wallage, Ph. (2008), De toekomst van het accountantsberoep - Verandering als enige constante, Maandblad voor Accountancy en Bedrijfseconomie, vol. 82, no. 3 (maart), pp. 74-76.

- Watts, R.L. en J.L. Zimmerman (1986), Positive accounting theory, Englewood Cliffs, $\mathrm{NJ}$ : Prentice Hall.

Noten

I In vaktermen wordt met zowel controle (audit) als assurance bedoeld: het verstrekken van zekerheid bij een verantwoording, waarbij de accountant toetst aan een verslaggevingsnorm. De term controle is in de regelgeving voor accountants voorbehouden aan toetsing van historische financiële informatie, assurance is het bredere begrip dat ook wordt gebruikt voor andere verantwoordingen dan historische financiële informatie (NIVRA, 2010a).

2 De Sociaal Economische Raad (SER) heeft hier bijvoorbeeld ook een rol in gespeeld. In 2000 publiceerde de raad 'De winst van waarden', waarin aandacht werd gevraagd voor de maatschappelijke aspecten van ondernemen. In 2008 volgde het SER-advies 'Duurzame globalisering: een wereld te winnen' gevolgd door de SER-verklaring 'Internationaal Maatschappelijk Verantwoord Ondernemen', die op 19 december 2008 werd gepubliceerd. 3 Zie voor een overzicht van de ontwikkelingen op dit gebied de duurzaamheidbarometer op www.pwc.nl/barometer.
4 Naar analogie van materieel onjuiste voorstelling van zaken inzake corporate governance-informatie in het jaarverslag kan hier gebruik worden gemaakt van Praktijkhandreiking 1109 (NIVRA, 2010b).

5 PwC geeft vanaf 2010 vanuit Nederland op basis van de Europese regelgeving (EU-ETS) assurance bij $40 \%$ van de 50 grootste luchtvaartmaatschappijen ter wereld over de $\mathrm{CO}_{2}$-uitstoot van vliegtuigen die op of over Europa vliegen. Deze werkzaamheden vinden plaats in multidisciplinaire teams onder leiding van een accountant. 